\title{
Identificação de potenciais plantas hospedeiras alternativas de Xanthomonas campestris pv. Viticola
}

\author{
Identification of potential alternative hosts of Xanthomonas campestris pv. Viticola
}

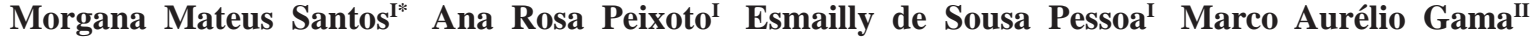
Rosa de Lima Ramos Mariano ${ }^{\mathrm{II}}$ Maria Angélica Guimarães Barbosa ${ }^{\mathrm{III}}$ Cristiane Domingos da Paz
\end{abstract}

\section{- NOTA -}

\section{RESUMO}

Este estudo teve como objetivo identificar possíveis hospedeiras alternativas de Xanthomonas campestris pv. viticola (Xcv), visando a fornecer subsídios para o manejo do cancro bacteriano da videira. Vinte e seis espécies vegetais foram inoculadas artificialmente com o isolado Xcv3 e mantidas em condições de casa de vegetação, sendo avaliada a evolução sintomatológica da doença, como manchas necróticas angulares e lesões nas nervuras. O Xcv3 foi reisolado a partir de cada hospedeiro alternativo com sintomas, sendo identificado por PCR (Polymerase Chain Reaction), com iniciadores específicos. As espécies inoculadas que apresentaram os sintomas típicos da doença foram Glycine sp., Senna obtusifolia, Desmodium discolor, Amaranthus deflexus, Azadirachta indica, Solanum lycopersicum e Vigna unguiculata. As espécies da família Poaceae, Bidens pilosa, Emilia fosbergii, Praxelis pauciflora, Macroptilium lathyroides e Portulaca oleracea não apresentaram sintomas durante o período da avaliação.

Palavras chaves: sobrevivência bacteriana, Cancro bacteriano da videira, Vitis vinifera, $P C R$ - específica.

\section{ABSTRACT}

This study aimed to identify potential alternative hosts of Xanthomonas campestris pv. viticola (Xcv), to provide data for the management of bacterial canker of grapevine. Twenty-six plant species were artificially inoculated with the strain Xcv3 and maintained under greenhouse conditions where the development of disease symptoms, such as angular necrotic spots and rib lesions were evaluated. The Xcv3 was reisolated from each symptomatic alternative host, and identified using PCR (Polymerase Chain Reaction) with specific primers. The inoculated species that showed typical disease symptoms were Glycine sp., Senna obtusifolia, Desmodium discolor, Amaranthus deflexus, Azadirachta indica, Solanum lycopersicum and Vigna unguiculata. Species of the family Poaceae, Bidens pilosa, Emilia fosbergii, Praxelis pauciflora, Macroptilium lathyroides and Portulaca oleracea were not showed during the period of evaluation.

Key words: bacterial survival, bacterial canker of grapevine, Vitis vinifera, PCR-specific.

O cancro bacteriano, causado por Xanthomonas campestris pv. viticola (Xcv) (Nayudu) Dye, é uma importante doença da videira no Submédio do Vale do São Francisco, com incidência expressiva, causando perdas significativas em cultivares suscetíveis (MALAVOLTA Jr. et al., 2003). Em condições adversas, a Xcv tem a capacidade de sobreviver de um ciclo para outro em videiras, bacelos e mudas infectadas (ARAÚJO, 2001) e em hospedeiras alternativas (PEIXOTO et al., 2007). Segundo SILVA et al. (2012), a Xcv é capaz de sobreviver em altas populações em restos de poda de videira infectados durante, pelo menos, 80 dias do ciclo da cultura. A determinação do círculo de hospedeiras de fitopatógenos, com a identificação de suas hospedeiras alternativas potenciais, é um passo importante para elaboração de estratégias de manejo da doença. Assim, o objetivo deste estudo foi identificar plantas espontâneas, plantas de interesse comercial e de uso como quebra-vento, na região, como potenciais hospedeiras alternativas de Xcv.

Foram testadas 19 espécies de plantas espontâneas (Amaranthus deflexus L., Bidens pilosa DC., Eclipta alba (L.) Hassk, Emilia fosbergii Nicolson, Praxelis pauciflora (Kunth), Tridax

\footnotetext{
IDepartamento de Tecnologia e Ciências Sociais (DTCS III), Universidade do Estado da Bahia (UNEB), 48905-680, Juazeiro, BA, Brasil.

E-mail: morganamateuss@gmail.com.*Autor para correspondência.

ID Departamento de Agronomia, Área Fitossanidade, Universidade Federal Rural de Pernambuco (UFRPE), Recife, PE, Brasil.

IIIEMBRAPA Semiárido,Petrolina, PE, Brasil. 
procumbens L., Mormodica charantia L., Leonotis nepetifolia (L.) R. Br., Desmodium discolor Vogel, Macroptilium lathyroides (L.) Urb, Glycine sp., Senna obtusifolia (L.) Irwin \& Barneby, Chloris barbata (L.) Swartz, Setaria geniculata P. Beauv., Eluesine indica (L.) Gaertn, Dactyloctenium aegyptium (L.) Willd, Digitaria horizontalis Willd., Cenchrus echinatus L., Portulaca oleracea L.), comumente encontradas nas áreas de produção de videira, cinco espécies de plantas de interesse comercial (Vignia unguiculata(L.) walp., Allium cepa L., Solanum lycopersicum, Cucumis melo L., Citrullus lanatus (Thunb.) \& Nakai, Curcubita pepo L.) e uma espécie de quebra-vento (Azadirachta indica A. Juss.), cultivadas no Submédio do Vale do São Francisco. As sementes das 26 espécies citadas foram plantadas em vasos com substrato 2:1:2 (Argila; areia; esterco) esterilizados em autoclave a $120^{\circ} \mathrm{C}$, por duas horas. Vinte dias após a emergência, essas espécies foram inoculadas artificialmente com Xcv 3 (isolado de Xanthomonas campestris pv. viticola, pertencente ao Laboratório de Fitopatologia DTCS/ UNEB, Juazeiro, BA.), pelo método de dupla gaze com suspensão cuja concentração foi de $10^{8} \mathrm{ufcml}^{-1}$ preparada em ADE (Água Destilada e Esterilizada) com Tween (NASCIMENTO et al., 2005) e o isolamento foi feito com 42 dias após a inoculação nas plantas que manifestaram sintomas. Foram incluídos controles negativos para cada espécie testada (inoculadas apenas com ADE + Tween 20). A inoculação foi realizada em cinco folhas por planta, cada planta representando uma repetição. Mudas de videira 'Thompson seedless' foram utilizadas como padrão de suscetibilidade (NASCIMENTO et al., 2006). As plantas foram mantidas em condições de casa de vegetação, com temperatura e umidade relativa em torno de $30^{\circ} \mathrm{C}$ e $75 \%$, respectivamente. As avaliações tiveram início 48 horas após a inoculação artificial. As plantas foram avaliadas, diariamente, até os 42 dias da inoculação, avaliando a evolução do quadro sintomatológico da doença, como manchas necróticas angulares e lesões nas nervuras. O experimento foi repetido duas vezes, apresentando 27 tratamentos e cinco repetições por tratamento.

As análises moleculares foram realizadas no Laboratório de Fitobacteriologia da Universidade Federal Rural de Pernambuco (UFRPE), Recife, PE, com a finalidade de confirmar a identidade de todos os isolados obtidos de folhas inoculadas das diferentes espécies que manifestaram sintomas. A extração do DNA genômico dos isolados que se mostraram patogênicos tanto nas hospedeiras alternativas quanto nas mudas de videira cv. Thompson seedless foi realizado segundo a metodologia de AUSUBEL et al. (1992). A identificação molecular dos isolados foi realizada utilizando-se os iniciadores $\mathrm{Xcv} 1 \mathrm{~F} / \mathrm{Xcv} 3 \mathrm{R}$, para amplificação de um fragmento de $243 \mathrm{pb}$ do gene hrpB, segundo a metodologia de TRINDADE et al. (2007). Reações livres de DNA foram incluídas nas análises para assegurar a ausência de contaminantes. Amostras do DNA dos isolados de $\boldsymbol{X}$. campestris pv. viticola, Xcv 3 e IBSBF 2738 (obtido da Coleção de Culturas de Fitobactérias do Instituto Biológico), foram incluídos como controle positivo. As reações foram amplificadas em termociclador modelo MJ96 (Biocycler). Após a amplificação, $12 \mu 1$ de cada reação foram misturados a $3 \mu \mathrm{l}$ do tampão de carregamento e a 2,5 $\mu \mathrm{l}$ de Syber $^{\circledR}$ Safe, aplicando-se um volume total de $17,5 \mu \mathrm{l}$ em cada poๆo do gel. A visualização dos fragmentos amplificados foi realizada em gel de agarose a $1 \%$ preparado em tampão TBE $0,5 \mathrm{X}$. A corrida eletroforética foi realizada por $1 \mathrm{~h}$ e 10 min a $80 \mathrm{~V}$ em tampão TBE $0,5 \mathrm{X}$, utilizando-se como marcador $1 \mathrm{~kb}$-DNA Ladder (GenRuler $\left.{ }^{\mathrm{TM}}\right)$. Em seguida, o gel foi fotodocumentado.

Os sintomas observados nas folhas do tomateiro, feijão-de-corda, fedegoso, soja perene, amor-agarradinho, bredo, nim, erva-de-touro, cordão-de-frade e melão-de-são-caetano mostraramse semelhantes àqueles observados em videira, apresentando a evolução do quadro sintomatológico da doença. Os sintomas iniciaram com pequenas pontuações amareladas que evoluíam para manchas necróticas angulares e, posteriormente, apresentando lesões nas nervuras das folhas (Figura 1). Os sintomas observados em soja-perene, fedegoso e bredo confirmam as observações de PEIXOTO et al. (2007), que detectaram infecção natural por Xcv em parreirais comerciais do Submédio do Vale do São Francisco. Estudos realizados por KUROZAWA E PAVAN (2005) também verificaram a sobrevivência de Xanthomonas vesicatoria (Doidge), um dos agentes causais da mancha bacteriana do tomateiro, em plantas espontâneas como Amaranthus retroflexus L., Chenopodium album L., Datura spp., Digitaria sanguinalis (L.) Scop, Portulaca oleraceae, Setaria glauca (Poir.) Roem. \& Schult., Solanum nigrum L. e Physalis spp., constituindose em importantes fontes de inóculo do patógeno. As plantas de nim também se apresentaram como potenciais hospedeiras alternativas de Xcv, mostrando-se muito suscetíveis, confirmando o relato de NAYUDU (1972) e MOREIRA et al. (2006).

Todas as espécies testadas, pertencentes à família Poaceae, bem como picão-preto, erva-debotão, falsa-emília, couve-cravinho, feijão-miúdo, 


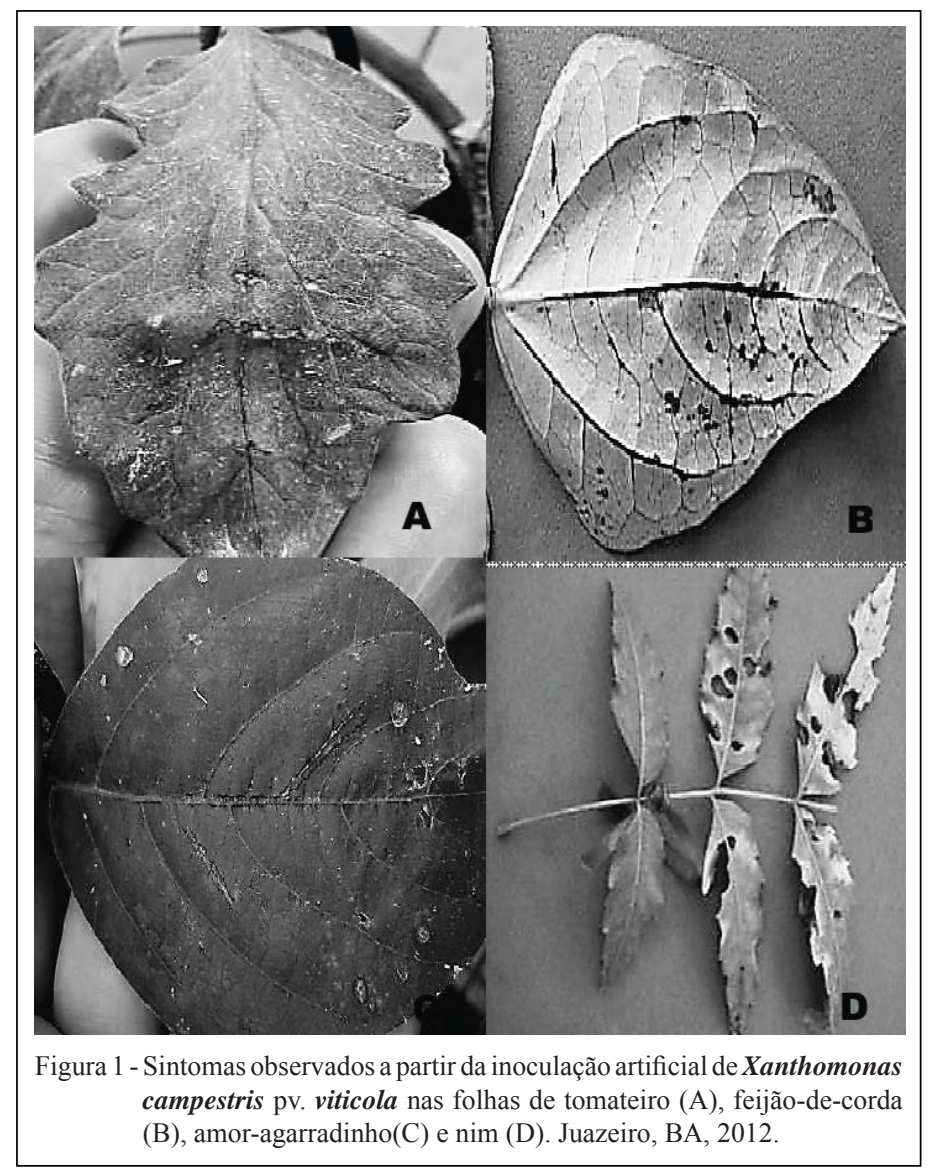

beldroega, e as cucurbitáceas, melão, abóbora e melancia, não mostraram sintomas quando inoculadas com Xcv, até os 42 dias de avaliação. Resultados semelhantes foram encontrados por NASCIMENTO et al. (2006), através de inoculação artificial de Xcv (método de dupla gaze com suspensão cuja concentração foi de $10^{8} \mathrm{ufcml}^{-1}$ ), em gramíneas. Eles verificaram que Eragrostis pilosa (L.) P. Beauv (capim barbicha-de-leão) e Dactyloctenium aegyptium (L.) Willd (capim mão-de-sapo), não manifestaram sintomas. Para outras Xanthomonas, as gramíneas também não são hospedeiras comuns, como exemplo, pode-se citar o trabalho realizado por MANTOVANI et al. (2006), que, ao inocular artificialmente 31 espécies de gramíneas, com Xanthomonas sp., verificaram que apenas o Sorghum bicolor (L.) Moench (sorgo), Zea mays L. (milho) e Avena sativa L. (aveia) apresentaram sintomas. Apesar do método agressivo de inoculação e das condições ambientais favoráveis, a bactéria não foi capaz de causar infecção nessas espécies testadas, mostrando não serem hospedeiras alternativas de Xcv.

Os DNAs genômicos purificados dos isolados bacterianos, obtidos dos diferentes hospedeiros que apresentaram sintomas e dos isolados utilizados como controle positivo (Xcv3 e IBSBF 2738), amplificados com os iniciadores $\mathrm{Xcv1F} / \mathrm{Xcv} 3 \mathrm{R}$, resultaram em fragmentos de aproximadamente $243 \mathrm{pb}$, quando visualizados em gel de agarose. Outros estudos também utilizaram de maneira bem sucedida os iniciadores Xcv1F/ Xcv3R para detecção e identificação de Xcv. Assim, Marques (2007) identificou 33 isolados de Xcv e MIRANDA (2011) foi capaz de detectar Xcv em uvas assintomáticas com baixa concentração de células $\left(\sim 10^{3} \mathrm{ufcml}^{-1}\right)$. Adicionalmente, a técnica de PCR está sendo muito usada para detectar e identificar fitopatógenos, incluindo várias bactérias fitopatogênicas (MOLTMANN \& ZIMMERMANN, 2005; PARK et al. , 2007).

É evidente a importância do estudo das hospedeiras alternativas de Xcv, pois a sobrevivência do patógeno nos parreirais pode estar relacionada aos cultivos de tomateiro e feijão-de-corda em áreas próximas às videiras, às plantas espontâneas, como: amor-agarradinho, bredo, fedegoso, soja-perene, ervade-touro e cordão-de-frade, além do plantio do nim como quebra-vento ou em áreas próximas aos parreirais. 


\section{REFERÊNCIAS}

AUSUBEL, F. M. et al. Current protocols in molecular biology. Vol. 1. Greene Publishing Association, New York. 1992.

ARAÚJO, J.S.P. Perfil epidemiológico e subsídios para o controle de Xanthomonas campestres pv. viticola (Nayudu) Dye, agente do cancro bacteriano da videira (Vitis vinifera) no Brasil. 2001. 121p. tese (Doutorado em fitotecnia) - Universidade Federal Rural do Rio de Janeiro. Rio de Janeiro. 2001

KUROZAWA, C. \& PAVAN, M. A. Doenças do tomateiro. In: HIROSHI KIMATI et al. Manual de Fitopatologia. 4.ed. São Paulo: Ceres, 2005. v.2, p.614-615

MALAVOLTA JR., V.A. et al. Resistência de Variedade de Videira a Xanthomonas campestris pv. viticola. Arquivo do Instituto Biológico, São Paulo, v.70, n.3, p. 373-376, jul./set. 2003.

MANTOVANI, E.S. et al. Gramíneas Hospedeiras de Xanthomonas $s p$, agente causal da falsa estria Vermelha da Cana-de-Açúcar. Summa Fitopatologia. [online], Botucatu, v.32, n.2, p. 124-130, 2006

MARQUES, E. Variabilidade e tolerância ao cobre em Xanthomonas campestris pv. viticola, agente causal do cancro bacteriano da videira (Vitis spp.). 2007. 129p. dissertação (Mestrado em Fitopatologia) - Universidade de Brasília. Brasília. 2007.

MIRANDA, T.V. Otimização da PCR para deteç̧ão de Xanthomonas campestris pv. viticola em videiras assintomáticas. 2011. 37p. monografia (Licenciatura em Biologia) - Universidade de Brasília. Brasília. 2011.

MOLTMANN, E. \& ZIMMERMANN, C. Detection of Xanthomonas fragariae in symptomless strawberry plants by nested-PCR. Bulletion OEPP/EPPO, Noordwijkerhout, v.3, p.53-54, 2005.
MOREIRA, W.A.; PEREIRA, A. V. S.; KARASAWA, M. \& ANTUNES Jr, E.F. Efeito da inoculação de Xanthomonas campestris pv. viticola em plantas de nim. Fitopatologia Brasileira. Londrina, v.31, p.282. 2006.

NASCIMENTO, A.R.P. et al. Reação de variedades de videira a Xanthomonas campestris pv. viticola, baseada nos componentes epidemiológicos do cancro bacteriano. Ciência Rural, Santa Maria, v.36, n.1, p.1-7, 2005.

NASCIMENTO, A.R.P. et al. Meio seletivo para Xanthomonas campestris pv. viticola. Ciência Rural, Santa Maria, v.36, n.4, p.1317-1320. 2006.

NAYUDU, M. V. Pseudomonas viticola sp. nov., incitant of a new bacterial disease of grape. Phytopathologische Zeitschrift, Berlin, v. 73, p. 183-186, 1972.

PARK, D.S. et al. Sensitive and specific detection of Xanthomonas campestris pv. vesicatoria by PCR usisng pathovar-specific primers based on rhs family gene sequences. Microbiological research. Jena, v.164, p.36-42, 2007.

PEIXOTO, A.R. et al. Hospedeiras alternativas de Xanthomonas campestris pv. viticola. Fitopatologia Brasileira, Londrina, v.32, n.2, p, 161-164, 2007.

SILVA, A.M.F. et al. Sobrevivência de Xanthomonas campestris pv. viticola em tecido infectado de videira. Revista Brasileira de Fruticultura. Jaboticabal - SP, v. 34, n. 3, p. 757-765, 2012.

TRINDADE, L.C. et al. Development of a molecular method for detection and identification of Xanthomonas campestris pv. viticola. Summa Phytopathologica, Botucatu, v. 33, n. 1, p. 1623, 2007. 